\title{
Research Article Abstracts in Two Subdisciplines of Business-Move Structure and Hedging between Management and Marketing
}

\author{
Qian $\operatorname{Li}^{1} \&$ Issra Pramoolsook ${ }^{1}$ \\ ${ }^{1}$ School of Foreign Languages, Institute of Social Technology, Suranaree University of Technology, Nakhon \\ Rachasima, Thailand \\ Correspondence: Qian Li, School of Foreign Languages, Institute of Social Technology, Suranaree University of \\ Technology, Nakhon Rachasima 30000, Thailand. Tel: 66-083-684-5761. E-mail: qian2007816@gmail.com
}

\author{
Received: August 27, 2014 Accepted: October 30, 2014 Online Published: December 17, 2014 \\ doi:10.5539/elt.v8n1p52 URL: http://dx.doi.org/10.5539/elt.v8n1p52
}

\begin{abstract}
The importance of RA abstracts lies in their influence on the readers' decision about whether the accompanying article is worth reading. A number of studies have investigated the move structure of abstracts and have generated several influential models. However, little research has been conducted on subdisciplinary variations in move structure of abstracts. Additionally, previous studies have investigated independently either the move structure or the hedging use of academic writings. The attempt of the integration of the both have been lacking yet. Therefore, this study reports the analysis of move structure and hedging use in Management and Marketing abstracts. Comparative analysis was also conducted to investigate sudisciplinary variations in both move structure and hedging use between the two subdisciplines in the field of Business. In total, sixty-four research articles abstracts published in 2012 were randomly selected form eight leading journals in two subdisciplines. Hyland's model (2000) was adopted as analytical framework for move structure analysis, and Wordsmith Tool was used to search hedging in the corpus. Results showed that the move structure of I-P-Pr (Introduction-Purpose-Product) is the most dominant sequences in both Management and Marketing. Regarding the use of hedging, all the five types occurred in both subdisciplines of Business. The findings of this study have also demonstrated the existence of variations in terms of both move structure and the use of hedging in the abstracts between the two subdisciplines. Therefore, pedagogical implications can be proposed that teaching practices should address the variations so as to meet the specific expectations from different particular discourse communities.
\end{abstract}

Keywords: business RA, abstracts, move structure, hedging, subdisciplinary variations

\section{Introduction}

RA abstracts have become a separate, well-established genre in academic discourse since the discourse community of scholars has asked for RA abstracts as orienting tools for their reading (Gillaerts \& Velde, 2010). An abstract is sometimes called 'a summary' because it presents a faithful and accurate summary, which is representative of the whole article ((Bhatia, 1993), and it attempts to summarize the main features and findings of the accompanying article (Bonn \& Swales, 2007). The Abstract is important because it influences the readers' decision about whether the accompanying article is worth reading. Swales (1990) proposes that Abstract is an advance indicator of the content and structure and a representation of an article. Despite sharing some common features of the RA, the Abstract constitutes a genre in its own right and it differs in its rhetorical structure (Lorés, 2004).

A number of studies have investigated the move structure of the Abstract. The influential research includes Bhatia (1993), Santos (1996), Hyland (2000), Martín (2003), Lorés (2004), and Samraj (2005). All these studies took Swales' CARS model (1990) as starting point and focused on the rhetorical components or 'moves' of abstracts in different settings.

Bhatia (1993) identifies a four-move framework for a typical abstract consisting of Introducing purpose, Describing methodology, Summarizing results, and Presenting conclusions. These four moves are correspondent with the information an abstract contains. Bhatia's (1993) four-move pattern structure is reported to be common structure in the Abstracts in Martin (2003) who identified four basic elements of I (Introduction)- $M$ (Methodology)- $R$ (Results)- $C$ (Conclusions). However, Santos (1996) proposes a five-move models for the 
abstract after analyzing 94 abstracts in Applied Linguistics, which is slightly different from that in Bhatia (1993) and Martin (2003). The IMRC pattern identified in Bhatia (1993) can be found in the last four moves in Santos' (1996) model which contains five moves and a number of submoves. The last four moves in Santos (1996) indicate the purpose, describe the methodology, summarize the results and discuss the research, respectively. The first move (Situating the research) is similar to the first move in Swales' CARS model (1990). The main function of this move in Santos' model is to establish a territory of the research which exactly corresponds with the first move in Swales' CARS model (1990).

Studies of disciplinary differences in the abstract have also been found. The most substantial one is Hyland (2000), who analyzes 800 abstracts from eight disciplines; namely, Biology, Physics, Electronic Engineering, Mechanical Engineering, Applied Linguistics, Marketing, Philosophy and Sociology. The rhetorical structure of abstracts varies considerably according to discipline. He proposes a five-move framework that contains corresponding components of Introduction, Purpose, Method, Product and Conclusion. Samraj (2005) also examines disciplinary differences in abstracts in two closely related disciplines of Wildlife Behavior and Conservation Biology. She analyzes 12 abstracts from each discipline and the findings show the variations occur even in abstracts of two related disciplines. The two studies described above confirm that the move structure of abstracts varies between and across different disciplines.

The above survey has indicated that a number of studies on investigation into the move structure have been conducted and have generated several models for RA abstracts. In addition, previous studies on disciplinary variations have shown that differences exist in move structure of abstracts in different disciplines. However, scant attention has been given to the move structure of Business RA abstracts though a wide range of disciplines have been focused on, including Biology, Physics, Electronic Engineering, Mechanical Engineering, Applied Linguistics, Marketing, Philosophy and Sociology. Additionally, to date, there has been only one case (Samraj, 2005) investigating the variations in RA abstracts between two related disciplines in the field of environmental science. Therefore, there is a need to investigate more about move structure of subdisciplines in Business and to identify subdisciplinary variations between them.

In contrast to move structure, the language of the RA abstract has received little attention. The present study attempts to focus on one aspect of linguistic features-hedging. Hedging is important in academic discourse because it contribute to an appropriate rhetorical and interactive tenor, conveying both epistemic and affective meanings (Hyland, 1998). It covers not only the sense of writer's degree of confidence in the truth of a proposition, but also an attitude to the audience. The writer can capitalize on hedging to express uncertainty about a position (Hu \& Cao, 2011). The crucial importance of hedging lies in the fact readers expect claims to be warranted in terms of the assessments of reliability they carry, and appropriate in terms of the social interactions they appeal to (Hyland, 2000).

In addition, hedging is an important means by which academics confirm their membership of research communities. A totally unhedged style would not be considered seriously by journal editors (Salager-Meyer, 1997). In other words, the writers who use hedges in their writing would have greater opportunities to get their paper published than those who do not use these devices.

A number of studies on hedging have been conducted. Previous studies indicate that the rhetorical conventions may vary from one genre to another (e.g. Salager-Meyer, 1994; Hyland, 1996a, 1999; Mizapour \& Mahand, 2012) and disciplinary variations exist in the use of hedging (e.g. Falahati, 2006; Millan, 2008). This confirms that the frequency and type of hedging and hedging techniques used in different disciplines may vary considerably.

Obviously, a substantial number of studies have investigated independently either the move structure or the hedging use of academic writings. However, the attempt of the integration of the both have been lacking yet. Clearer pictures of how RA abstracts are composed and how writers present claims for ratification should be provided.

Therefore, the present study aims to identify the move structure of RA abstracts form two subdisciplines, Management (Mgmt) and Marketing (Mkt), in the field of Business. Management is a subdiscipline and it is viewed as the process by which a manager of an organization efficiently utilizes resources to achieve its overall goals at minimum cost and maximum profit. Marketing has as long history as Management, both areas dated back to the Industrial Revolution in $18^{\text {th }}$ century. Marketing is a subdiscipline concerned with establishing and enhancing relationships with customers and other partners, and identifying and satisfying their requirements profitably. Another purpose of this study is to examine the type and frequency of hedging use in these two target subdisciplines described above. Comparing RA abstracts form these two subdisciplines will enable us to explore 
the applicability of the selected model across different disciplines and to perceive how hedging is employed in Business academic genre. The results from the two levels of comparative analysis would increase our better understanding of move structures and hedging use in different subdisciplines. We can better distinguish textual characteristics and be aware of particular linguistic features which are due to subdisciplinary norms. Thus, the findings may prepare novice researchers for successful communication in their particular field. Also, the results of this study have implications for teaching of Business RA abstracts to novice writers. In correspondence to the purposes, this study seeks to answer the following research questions:

1) What are the move structures of the Abstracts in Management and Marketing RAs?

2) What are similarities and differences in move structure of Abstracts between Management and Marketing RAs?

3) What are the type and frequency of hedging use in the Abstracts in Management and Marketing RAs?

4) What are the variations of the use of hedging in terms of type and frequency in Abstracts between the Management and Marketing RAs?

\section{Methodology}

\subsection{Data and Data Analysis}

To address the research questions of this current study, two levels of analysis move structure analysis and hedging analysis were carried out.

Sixty-four research article abstracts were randomly selected form eight journals, which are considered as leading journals in two subdisciplines Management and Marketing by specialists in the areas. All these articles were published in 2012 to avoid the chronological variation and to enhance the coherence and validity of the study's results (Kanoksolapatham, 2003).

Hyland's framework (2000) was adopted for analyzing the move structure of the Abstracts in this study. Move identification was carried out manually, which may suffer from subjectivity of move analysis. The inter-rater reliability was conducted to achieve higher reliability by working collaboratively of two people. The rater selected six texts randomly from each of two corpora. After that, the researcher and the rater analyzed these 12 abstracts independently. Then, the results of analysis were compared and the differences were discussed to reach the agreement.

As for the analysis of the use of hedging in the Abstract, the software of Wordsmith Tool was used to search hedging in the corpora. The type of hedges were identified based on five categories of hedging adapted from taxonomies proposed by Holmes (1988), Salager-Meyer (1994) and Hyland (1996b). These five categories of hedging are modal auxiliaries, epistemic lexical verbs, epistemic adverbs, epistemic adjectives and epistemic nouns. The frequency of incidences of hedges was calculated for per 1,000 words. The two corpora together contain about 10,000 running words in total (4 600 for Management; 5400 for Marketing).

\section{Results and Discussion}

After analyzing 64 Abstracts from the two corpora, the results are reported below from two perspectives: move analysis and analysis of hedging

\subsection{Move Analysis}

It was found that the most frequent move structure in the two corpora was the sequence of Introduction-Purpose-Product (I-P-Pr), comprising about $25 \%$ of all incidences in each corpus. Interestingly, this finding is different from that in Hyland (2000), who identified P-M-Pr as the dominant sequences in his corpus. The possible reason for this difference lies in the nature of the two corpora. Hyland's (2000) corpus contains texts from four hard disciplines and four soft disciplines. Basically, his results reveal that the texts from hard disciplines tend to describe the research methods, while the articles from the soft disciplines may focus more on the context or background of the research. Research scope or context, purposes of the study, and results are very crucial for the study in both the Management and Marketing abstracts, and these three elements are arranged in the sequence to present logical order (following the order of moves arranged in Hyland's model) in abstracts. The I-P-Pr pattern is illustrated below as (1):

(1) Becauseof the "opaque" nature of divestitures, investors face considerable uncertainty in evaluating divesture decisions and this may look to a firm's social context, defined in terms of the pervasiveness of divestiture activity in its industry, to infer the quality of such a decision. Specifically, we propose that a firm's position in an industry divestiture wave conveys information about whether or not manager are imitating their industry peers, 
which in turn will influence how investors perceive and assess the quality of the decision and its likely performance consequences. Supporting this theoretical argument, we find that the relationship between divestiture position and stock market returns exhibits a U-shaped pattern, with divestitures that occur at the peak of an industry divestiture wave generating the lowest stock market returns. We also find that industry characteristics (e.g., munificence) reinforce the effect of position social context, assessed in terms of the pervasiveness of an activity, as an important factor that influence how investors perceive and evaluate divestiture decisions. (Mgmt 7)

I-P-Pr-C, comprising $22 \%$ of all incidents, was the second most dominant pattern in Marketing corpus, while the second most frequent pattern in Management was P-Pr, accounting for $22 \%$ of all samples as well. This indicates that despite some similarities in the dominant structural pattern and frequency of occurrence of some moves in both corpora, differences also exist in Management and Marketing.

Moreover, the move embedment was a prominent feature in the data. The Method move was found to be heavily embedded in the Product move $(\mathrm{Pr} / \mathrm{M})$ in the management and marketing abstracts. Move embedment with more than one communicative purpose should be identified as one move with the dominant communicative purpose. In this case, the sentence with $\operatorname{Pr} / \mathrm{M}$ embedment is identified as the Product move. Such instances account for around $33 \%$ of the samples in total. Among them, $\mathrm{Pr} / \mathrm{M}$ embedment occurred in around $44 \%$ of the management abstracts, while only in about $22 \%$ of the marketing texts. It seems that writers in the field of management tended to combine results and method elements in one sentence more than writers in marketing. Examples (2) and (3) illustrate the embedment of $\operatorname{Pr} / \mathrm{M}$.

(2) Using data from 216 employees and their supervisors, results indicated that individuals were able to improve the otherwise negative odds of their creative ideas being realized when they expected positive outcomes to be associated with their implementation efforts and when they were skilled networkers or had developed a set of strong "buy-in" relationships. (Mgmt 6)

(3) Using a large longitudinal dataset with 1052 firms over 20 years, we find that firms decreasing from the top $20 \%$ to the bottom $20 \%$ of advertising spending group when compared to all industry competitors would experience a drop of abnormal return by $4.08 \%$ in 1 year and a cumulative total of $81.6 \%$ in 20 years. (Mkt 32)

Move cycle is also a very common feature, and was identified in previous studies (Bhatia, 1993; Hyland, 2000). However, only two cases of move cycle were identified and one incidence in each of the corpora. The move of Purpose has repeated once in Mgmt, and Method in Mkt occurred twice as well. The scarcity of move cycle may be due to the limited text length required by the journals in the two subdiciplines. It is difficult for writers to repeat a certain move within a limited space without missing other necessary elements in abstracts. Examples (4) and (5) display the move cycle in Mgmt and Mkt. The underlined parts are repeated moves.

(4) This paper explores the antecedents of work-life balance for employees as they progress through different career stages denoted by age. To date, research has failed to adequately explore how work-life balance issues develop over the course of an employee's working life ... This paper challenges the static approaches and instead seeks to examine if and how WLB is affected and shaped by different antecedents as they impact on differing career stages as defined by distinct age categorisations. (Mgmt 12)

(5) We study the cultural boundedness of TCE using two seminal cultural theories: the political science/sociology framework of Inglehart and the management science framework of Hofstede. We use these theories to develop (main-effect) hypotheses about the cultural contexts ... Hypotheses are tested using a meta-analysis on data collected from 128 studies from 12 countries on 3 continents, representing governance decisions of 60,926 companies. (Mkt 27)

It is worth noting that a new move which is not accounted for in Hyland's (2000) model was identified. The function of this new move was to promise the reader that the implications of practices or future research would be provided in the main body of the RA. The writers may attempt to save this actual implication without explicit description, and encourage the reader to continue reading the paper. Texts with similar purpose were found in TESOL Conference Abstracts and it was called 'Promising Implications' (Pramoolsook et al., 2014). 'Promising Implications' occurred once in each subdiscipline and is illustrated below as (6) and (7).

(6) Implications for research and practice are discussed. (Mgmt 17)

(7) Implications for the food and industry and policy makers are discussed. (Mkt 8) 
Table 1. Occurrence of moves in Mgmt and Mkt Abstracts

\begin{tabular}{lllll}
\hline \multirow{2}{*}{ Moves } & \multicolumn{2}{l}{ Management } & \multicolumn{2}{l}{ Marketing } \\
\cline { 2 - 5 } & Number & Percentage \% & Number & Percentage \% \\
\hline Introduction & 15 & 47 & 30 & 94 \\
Purpose & 28 & 88 & 28 & 88 \\
Method & 10 & 31 & 14 & 44 \\
Product & 30 & 94 & 31 & 97 \\
Conclusion & 12 & 37 & 15 & 47 \\
\hline
\end{tabular}

Table 1 summarizes the occurrence of move units in Mgmt and Mkt. The results reveal both similarities and differences in the frequency of occurrence of moves in the abstracts in two corpora. Obviously, the Purpose and Product move are the most frequent in the two sets of corpus and comprise similar proportion of occurrence respectively in both abstracts. However, the frequency of occurrence of the Introduction and Method move is quite different between the two corpora. Basically, the five moves are discussed and arranged based on the frequency of occurrence in the corpora. Thus, the moves of Purpose and Product with similar high frequency are discussed first, and the other three moves with low frequency are described afterwards.

\subsubsection{Purpose Move}

The Purpose outlines objectives and goals of the study, stating where the research will reach. Therefore, the Purpose indicates objectives, thesis or hypothesis, outlines the intention of the paper (Bhatia, 1993; Hyland, 2000). The results indicate that the majority of abstracts in the corpus contain this move. About $88 \%$ of Abstracts present the Purpose move in Mgmt and Mkt corpora. This confirms the finding that Purpose was one of the most frequently occurred moves in Samraj (2005). Such high occurrence may lie in the fact that the goals and intention of the study are very crucial to research in both subdisciplines. The objectives or goals may not only guide the writer to the expecting destination, but also help the reader judge the value of the study. Examples (8) and (9) display the Purpose move found in this study:

(8) This paper examines the effects of the family ownership with respect to the processes of firm internationalization. (Mgmt 9)

(9) This article proposes a generalized theory of healthful indulgences, identifying when and why people overconsume versus regulate food intake in response to health claims. (Mkt 8)

\subsubsection{Product Move}

The Product move presents the main findings of the study, suggesting an outcome that the reader may find interesting or surprising. Basically, the Product states main results, the argument, or what have been achieved. The most striking feature of the data is that almost all abstracts contain the Product move to report the research outcomes, accounting for around $95 \%$ of the texts in the corpora (94\% in management and 97 in marketing abstracts). This is consistent with Hyland's (2000) finding that the Product statement was the most frequently occurred move in about 94\% in his corpus. Also, this finding is supported by Martín (2003) and Samraj (2005). The high rate of appearance of the Product move indicates the extreme importance of findings or results in research. The writers are anxious to display the most central results to attract reader attention and they are eager to be accepted by the reader. The Purpose move reminds the writer to the right destination, while the Product move announces that the final goal has been achieved. Examples (10) and (11) below are two incidences of the Product Move:

(10) In the case of Russia, the benefits were found to exceed the costs, as corruption distance and anti-corruption legislation in force in the home country are positively related to share ownership. (Mgmt 19)

(11) We find that higher brand-equity-associated brand utility leads to higher choice consistency, which can drive increases in market share. (Mkt 13)

\subsubsection{Introduction Move}

According to Hyland (2000), the Introduction move sets the scene for the reader, providing essential background to the article, and indicates the significance of the topic to the target community and the writer's grasp of the issues involved. The function of the Introduction move is to establish context of the article and to motivate the research or discussion. The Introduction move occurred in 15 abstracts in the Mgmt corpus, and in 30 texts in the 
Marketing data, comprising around $47 \%$ and $94 \%$ of the samples respectively. In other words, much more Marketing abstracts include the introductory component than Management texts do. The difference resulting from disciplinary boundary is supported by Hyland (2000), Samraj (2002, 2005), Ozturk (2007). The results from all these studies indicate that differences in the structural organization of the RA Introduction occur between or across disciplines or subdisciplines, and these differences can be explained by the nature of disciplines or subdiciplines. Interestingly, the Introduction either focused on the context or background of the research or tended to explain why the present study was needed by reviewing the previous studies and indicating the research gap. Examples (12) and (13) illustrate these two types of Introduction.

(12) The increased contribution of entrepreneurs around the world necessitates the understanding of universal as well as culture-specific antecedents of entrepreneurial firm growth. (Mgmt 20)

(13) Prior research on brand equity suggests that consumers use brands as signals to reduce uncertainty and perceived risk. Erdem and Swait (1998) developed a conceptual framework based on information economics and signaling theory to explain how equity is created, maintained and transferred over time that involves seven theoretical constructs. (Mkt 13)

\subsubsection{Method Move}

The Method move provides a description of research design, procedures, data and approach (Hyland, 2000). Table 1 shows that $31 \%$ of the Management Abstracts included this move, while $44 \%$ of Marketing texts contained this move. Generally, occurrence of this move was low both of the corpora, which is consistent with Martín's (2003) and Samraj's (2005) findings that their corpora contained the least Method move. One possible reason for the low occurrence is because it was highly embedded in other moves. The findings showed that there were 17 incidences of the Method embedment in the Production or the Purpose in Mgmt, and only 8 cases in Mkt. This indicates that actually $77 \%$ of Abstracts described the methods used in the research, but some of the non-stand-alone method elements do not function as an independent move. The following Examples of (14) and (15) present the Method move:

(14) The data were collected from 2572 U.S. Army soldiers representing three organizational levels deployed in combat. (Mgmt 5)

(15) To address this issue, they examine a unique data set that combines a broad set of seven marketing-mix instruments with private-label share, using two decades' worth of data for 106 consumer packaged goods categories in the United States. (Mkt 17)

\subsubsection{Conclusion Move}

The Conclusion move interprets results and draws conclusions of the study. It usually extends results beyond the scope of paper and points to applications or wider implications. About $37 \%$ of writers in the Mgmt corpus included the Conclusion move in their abstracts, while nearly half of Marketing Abstracts contained this move. That is, more Marketing than Management Abstracts present this move as the final component to discuss the results beyond the actual data displayed. In general, the Conclusion move is a less common element in the two corpora, which can be assumed that the conclusion of the study is not very necessary because the reader can interpret and evaluate the study based on the present outcomes. In addition, the writer might intentionally create suspense and allow the reader to explore applications or implications by themselves later in the article. Examples (16) and (17) are two incidences of the Conclusion move:

(16) These results suggest that these different governance mechanisms resolve, to some extent, the existing divergence of interests between stakeholders and managers with respect to environmental activities. (Mgmt 29)

(17) Subsidiary performance outcomes, subsidiary environmental conditions including important marketing aspects (e.g., customer characteristics), and headquarters' coordination and communication mechanisms enrich our cluster description and yield a holistic picture of our marketing subsidiary taxonomy. The empirical results provide significant theoretical and managerial implications. (Mkt 28)

\subsection{Hedging Analysis}

The results from hedging analysis were reported on the type, frequency and variations between the Mgmt and Mkt corpus. Additionally, some examples of hedging used in the two corpora were provided to illustrate the functions of hedging in particular texts.

\subsubsection{Types and Frequencies of Hedging}

Table 2 presents the types and their percentages of hedging used in the Management and Marketing Abstracts. All five types of modal auxiliaries, epistemic lexical verbs, epistemic adverbs, epistemic adjectives and 
epistemic nouns were found to be used in both corpora. The total raw number of hedges used in the Management Abstracts was 88 within 4573 running words, and it was 116 within 5442 running words in Marketing. The epistemic lexical verbs were the most heavily used type among the five, accounting for $37.6 \%$ and $42.2 \%$ of the total hedges used in Mgmt and Mkt corpora, respectively. In contrast, an epistemic adverb was the least used type in Mgmt (10.2\%), while epistemic nouns were least employed in Mkt (5.2\%).

Table 2. Types and percentages of hedging of Mgmt and Mkt Abstracts

\begin{tabular}{lllll}
\hline \multirow{2}{*}{ Hedging } & Mgmt & \multicolumn{3}{l}{ Mkt } \\
\cline { 2 - 5 } & Raw Number & $\%$ & Raw Number & $\%$ \\
\hline Modal auxiliaries & 19 & 21.6 & 37 & 31.9 \\
Epistemic lexical verbs & 33 & 37.6 & 49 & 42.2 \\
Epistemic adverbs & 9 & 10.2 & 17 & 14.7 \\
Epistemic adjectives & 12 & 13.6 & 7 & 6.0 \\
Epistemic nouns & 15 & 17 & 6 & 5.2 \\
Total & 88 & 100 & 116 & 100 \\
\hline
\end{tabular}

Figure 1 displays the frequencies of occurrence of hedges in the Abstracts in the two subdisciplines per 1000 words. The Management Abstracts used around 19.2 per 1000 words, and about 21.3 per 1000 words were employed in the Marketing. The numbers indicate that slight difference in terms of the frequency of hedging use still existed in these two subdisciplines. Obviously, writers in the Marketing Abstracts tend to include more hedges than writers in Management. The possible reason could be that the Marketing subdiscipline is basically concerned with the enhancement of relationship with customers and partners to achieve maximum profits. Good relationship establishing requires good communications and proper strategies. Thus, writers in Marketing also know how to establish the relationship with the audience and hope to be accepted by them through using more hedges in the writing.

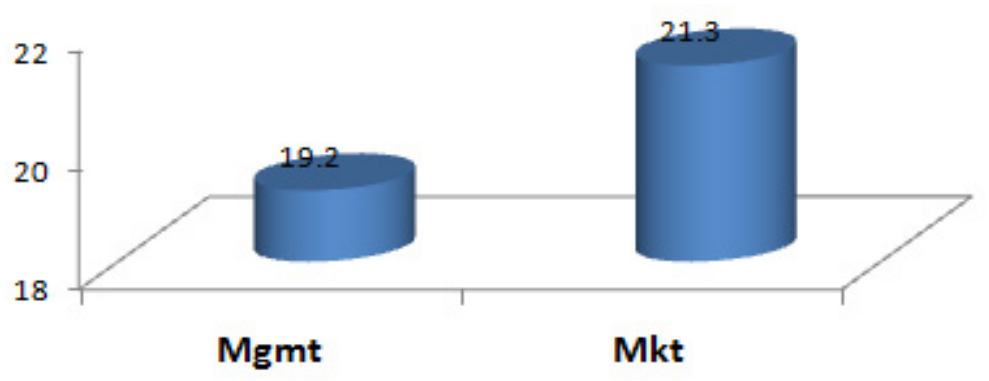

Figure 1. Frequencies of hedges in Mgmt and Mkt Abstracts per 1000 words

Figure 2 shows the frequencies of each type of hedges in the two subdisciplines. It also visually reveals the similarities and differences in their use. The frequency of lexical verbs in per 1000 words were 7 and 9 in Management and Marketing texts respectively, indicating that it was the most used type among five types in both corpora. This finding confirms their popularity inHyland (1996a) and Falahati (2006). Figure 2 also presents that modal auxiliaries was the second most utilized type in both subdisciplines (4.2 per 1000 words for Mgmt; and 6.8 per 1000 words for Mkt). Although epistemic lexical verbs and modal auxiliaries are the two most used types of hedges in both subdisiciplines, their hedging is different in terms of the frequency of occurrence. On the contrary, the categories of Epistemic adjectives and nouns were the least used ones in Marketing (1.3 per 1000 words), whereas Epistemic adverbswas the least employed category in Management (1.9 per 1000 words). 


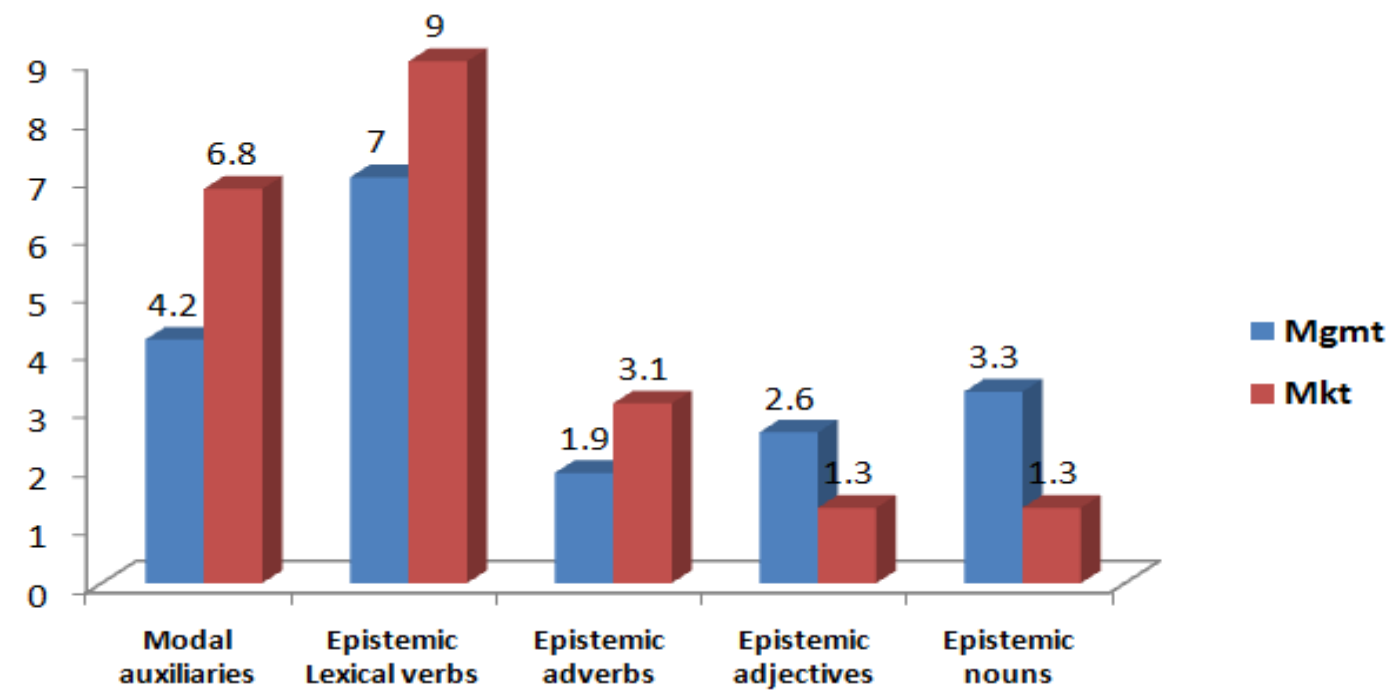

Figure 2. Frequencies of each type of hedges in Mgmt and Mkt Abstracts per 1000 words

The following two sections present some examples of hedges and provide possible explanations of their functions in the Management and Marketing corpora.

\subsubsection{Hedging in Management}

Three tokens of hedging elements were found in example [1]. The author is aware of the acceptable ways to modulate his statement. In addition, the author tries to be modest when interpreting his results. The first token "relatively" was used to tone down the statement to avoid the criticism for making full commitment to the truth (Hyland, 1996a). The second token "Hypotheses" indicates the author's uncertainty about his propositions which would be either accepted or rejected.

[1] Drawing upon organizational justice and social network theories, we examined the role of social network structure and content in the development of justice climates in self-managing teams, a relatively understudied context in the justice literature. Data from 79 project teams were used to test the hypotheses. Our results indicate that team instrumental network density is positively related to procedural justice climate strength and that this relationship is strengthened by low team functional background diversity. (Mgmt 4)

In Example [2], four tokens of hedging elements were identified. The use of "propose" shows that the author is eager to establish a close relationship with the reader. While the use of "will" refers to general truth, the justification for the assurance being based on repeated experience rather than logical inference (Hyland, 1996a). Additionally, the author tries to create vagueness or ambiguity by using the hedge word "likely" in [2] and [3] (Vázquez\&Giner, 2008).

[2] ..., investors face considerable uncertainty in evaluating divesture decisions and this may look to a firm's social context, defined in terms of the pervasiveness of divestiture activity in its industry, to infer the quality of such a decision. Specifically, we propose that a firm's position in an industry divestiture wave conveys information about whether or not manager are imitating their industry peers, which in turn will influence how investors perceive and assess the quality of the decision and its likely performance consequences. (Mgmt 7)

[3] However, in the mining industry, Chinese and Indian acquisitions are more likely to take place in resource-rich countries with unstable political environments, poor rule of law, and deficient control of corruption. (Mgmt 13)

The author in Example [4] interprets his findings in a safe way to avoid taking risks by using "theoretically" which indicates the findings may not be applicable in actual world. The use of "should" expresses the vagueness and politeness to avoid confrontation between writers and readers (Hyland, 2008; Vázquez \& Giner, 2008).

[4] Theoretically the findings offer a better understanding of referral behaviour; managerially, they can help firms amplify their new customer acquisition efforts by indicating which customer groups they should target with referral reward programs. (Mgmt10)

The tokens of "implication" in Example [5] and "assumption" in Example [6] are under the type of "Epistemic nouns". The author interprets his findings cautiously by using "implication" along with "may" in Example [5]. 
While "assumption" indicated that the untested claim "the importance of "market mavens' in purchase decision" needs empirical studies to justify. In this way, the author may attempt to allow more room for negotiation (Hyland, 1996c).

[5] The implication of the finding is that using contingent rewards may only be effective when implemented in a polite, respectful manner represented by interpersonal fairness. (Mgmt 16)

[6] Market mavens reportedly play important roles in the purchase decisions of other consumers, but this assumption has never been tested empirically. (Mkt 10)

\subsubsection{Hedging in Marketing}

Marketing is a fairly socially driven subject area that focuses on the habits and conventions of certain communities. The nature of this science seems to strongly influence the use of interactional elements like hedges (Vázquez \& Giner, 2008) because the data in this discipline are not be very numerical or mathematically verifiable, but based on opinions.

In the following Examples [7] and [8], a similar function was identified in the use of hedges "provided that" and "if" which belongs to "Epistemic adverbs" category. The writer is trying to assert something tentatively and avoid absolute statements which might put himself in an embarrassing situation (Salager-Meyer, 1994). The use of "tendency" indicates the possibility of the stated situations in the study, and the token "should" signals author's attention of showing uncertainty and his carefulness of not conveying rigid proposition.

[7] They find that increasing the fund assortment size decreases the tendency to invest in all available funds $(1 / \mathrm{n} \#)$ but increases the tendency to spread the invested dollars evenly among the chosen alternatives $(1 / \mathrm{n} \$)$, provided that the number of funds chosen for investment allows for easy equal dollar allocations. (Mkt 10)

[8] If the product development team wants to reduce resistance to products with market newness, it needs to build a coalition of supporters that can help it during the review process. Similarly, if the team seeks to minimize resistance to products with technology newness, it should frame the product in terms of the firms' existing products, strategies, and competitive thrusts. (Mkt18)

The token "consistent with" occurred twice in Example [9], and it was used when the author presents his findings with the support of previous studies or conceptualization to avoid the risk of being criticized once different results are obtained by other researchers. The hedging allows the writer to anticipate possible negative consequences of being proved wrong (Hyland, 1996c).

[9] Consistent with this perspective, five studies demonstrate that attribute numerosity benefits hedonic more than utilitarian options by increasing the extent to which the former appear useful ...Consistent with this conceptualization, these effects become amplified when decision makers engage in heuristic processing and when priming makes usefulness salient. The findings have important implications for how marketers present attribute information, for public policy and consumer welfare, and for understanding argument numerosity effects in persuasion more broadly. (Mkt 7)

Three tokens from "epistemic lexical verbs" were used in Example [10]. Hedging verbs represent an overt means of displaying the subjectivity of the epistemic source (Hyland, 1996a). The use of impersonal verbs "assume", "proposes" and "suggest" expresses the extent to which the writer commits himself to the truth value of the statements and the writer to be more open to other possible interpretation (Salager-Meyer, 1994). In addition, these hedges convey politeness.

[10] Marketers commonly assume that health claims attached to otherwise unhealthful food stimulate consumption because such claims offer justification for indulgence and reduce guilt. This article proposes a generalized theory of healthful indulgences, identifying when and why people overconsume versus regulate food intake in response to health claims. The authors suggest that the nature of the food attributes the claims emphasize - namely, functional versus hedonic — determines the extent of consumption of the indulgence. (Mkt 8)

Example [11] contains an "epistemic nouns" type of "probability" which is used to obscure the source of epistemic judgment, creating intentional ambiguity of statement.

[11] There is a high probability (61\%) that a price promotion affects sales of at least one other category. (Mkt 31)

The token "more or less", under the "Epistemic adverbs" category, can provide the reader with an alternative interpretation for the rest of the sentence (Hyland, 1996a), and balance against the convictions and expectations of readers (Hyland, 2008). 
[12] More or less advanced tasks can be found within all activities, e.g., in sales and marketing where telesales is on the less advanced end of the scale while branding and identity building are on the advanced end of the scale. (Mkt 25)

In summary, claiming precision is not appropriate in all situations and that scientists do not always want to be precise (Myers, 1989). The writers can modulate their statements in proper ways, highlight the subjectivity of a proposition, reduce the writers' commitment, convey sense of politeness and reduce confrontation between the writer and the reader (Salager-Myer, 1994; Vázquez \& Giner, 2008). It is an effective way to create rapport relationship between the writer and the reader because the former takes the latter into consideration and attempts to get the reader involved in their writing.

\section{Conclusion}

Despite various patterns of abstracts reported in this study, the move structure of I-P-Pr (Introduction-Purpose-Product) is the most dominant sequences in both Management and Marketing. In regarding with the individual move, both corpora contain more or less equal number of the moves of Product and Purpose. In contrast, differences occur in the use of moves of Introduction, Method and Conclusion in these two subdisciplines. Marketing Abstracts tend to include much more Introduction and Method moves than Management, while Management texts seem to contain more Conclusion element than Marketing.

Regarding the use of hedging, all the five types occurred in both subdisciplines of Business. Among them, "Epistemic lexical verbs" were found to be the most frequently used type in both corpora. Interestingly, "Modal auxiliaries" occurred with the same frequency in Management and Marketing. However, despite these similarities, some differences were still identified in terms of the frequency of hedging use in the two subdisciplines. Management abstracts tend to use more "epistemic nouns" and "epistemic adjectives" than Management samples, while writers in Marketing are likely to use more "epistemic lexical verbs".

In summary, the findings of this study have demonstrated the existence of variations in terms of both move structure and the use of hedging between the two subdisciplines of Business, i.e. Management and Marketing. Therefore, pedagogical implications can be proposed that teaching practices should address the variations so as to meet the specific expectations from different particular discourse communities.

\section{References}

Bhatia, V. K. (1993). Analyzing Genre: Language in professional settings. London: Longman.

Bonn, S. V., \& Swales, J. M. (2007). English and French journal abstracts in the language sciences: Three exploratory studies. Journal of English for Academic Purposes, 6(2), 93-108. http://dx.doi.org/10.1016/j.jeap.2007.04.001

Falahati, R. (2006). The use of hedging across different disciplines and rhetorical sections of research articles. Papers from the 22nd Northwest Linguistics Conference.

Gillaerts, P., \& Velde, F. V. (2010). Interactional metadiscourse in research article abstracts. Journal of English for Academic Purposes, 9, 128-139. http://dx.doi.org/10.1016/j.jeap.2010.02.004

Holmes, J. (1988). Doubt and certainty in ESL textbooks. Applied Linguistics, 9(1), 20-44. http://dx.doi.org/10.1093/applin/9.1.21

Hu, G. W., \& Cao, F. (2011). Hedging and boosting in abstracts of applied linguistics articles: A comparative study of English and Chinese medium journals. Journal of Pragmatics, 43, 2795-2809. http://dx.doi.org/10.1016/j.pragma.2011.04.007

Hyland, K. (1996a). Talking to academy: Forms of hedging in science research articles. Written Communication, 13(2), 251-281. http://dx.doi.org/10.1177/0741088396013002004

Hyland, K. (1996b). Writing without conviction? Hedging in scientific research articles. Applied Linguistics, 17(4), 433-454. http://dx.doi.org/10.1093/applin/17.4.433

Hyland, K. (1996c). Nurturing hedges in the ESP curriculum. System, 24(4), 477-490. http://dx.doi.org/10.1016/S0346-251X(96)00043-7

Hyland, K. (1998). Boosting, hedging and the negotiation of academic knowledge. Text, 18(3), $349-382$. http://dx.doi.org/10.1515/text.1.1998.18.3.349

Hyland, K. (1999). Talking to students: Metadiscourse in introductory coursebooks. English for Specific Purposes, 18(1), 3-26. http://dx.doi.org/10.1016/S0889-4906(97)00025-2 
Hyland, K. (2000). Disciplinary Discourses. London: Longman.

Hyland, K. (2008). Persuasion, Interaction and the construction of knowledge: Representing self and others in Research writing. International Journal of English Studies, 8(2), 1-23.

Kanoksilapatham, B. (2003). A corpus-based investigation of scientific research articles: Linking move analysis with multidimentional analysis (Unpublished doctoral dissertation). Georgetown University, Washington, DC.

Lorés, R. (2004). On RA abstracts: From rhetorical structure to thematic organization. English for Specific Purposes, 23(3), 280-302. http://dx.doi.org/10.1016/j.esp.2003.06.001

Martín, P. M. (2003). A genre analysis of English and Spanish research paper abstracts in experimental social sciences. English for Specific Purposes, 22(1), 25-43. http://dx.doi.org/10.1016/S0889-4906(01)00033-3

Millan, E. L. (2008). Epistemic and Approximative Meaning Revisited: The use of hedges boosters and approximators when writing research in different disciplines. In S. Burgess, \& P. Martín-Martín (Eds.), English as an Additional Language in Research Publication and Communication (pp. 65-82). Peter Lang, Bern, Germany.

Mirzapour, F., \& Mahand, M. R. (2012). Hedges and boosters in native and non-native library and information and computer science research articles. The Southeast Asian Journal of English Language Studies, 18(2), $119-128$.

Myers, G. (1989). The pragmatics of politeness in scientific articles. Applied Linguistics, 10, 1-35. http://dx.doi.org/10.1093/applin/10.1.1

Ozturk, I. (2007). The textual organization of research article introductions in applied linguistics: Variability within a single discipline. English for Specific Purposes, 26(1), 25-38. http://dx.doi.org/10.1016/j.esp.2005.12.003

Pramoolsook, I., Nguyen, T. T. L., Nguyen, D. L., \& Li, Q. (2014). Teachers of English to Speakers of Other Languages Conference Abstracts: Discrepancies between Potential Writers' Knowledge and Actual Composition. Presentation at 12th International Conference on New Directions in the Humanities, CEU San Pablo University, Madrid, Spain, June.

Salager-Meyer, F. (1994). Hedges and textual communicative function in medical English written discourse. English for Specific Purposes, 13(2), 149-170. http://dx.doi.org/10.1016/0889-4906(94)90013-2

Salager-Meyer, F. (1997). I think that perhaps you should: A study of hedges in written scientific discourse. In T. Miller (Ed.), Functional approaches to written text: Classroom applications. Washington, D.C: United States Information Agency.

Samraj, B. (2002). Introductions in research articles: Variations across disciplines. English for Specific Purposes, 21(1), 1-17. http://dx.doi.org/10.1016/S0889-4906(00)00023-5

Samraj, B. (2005). An exploration of a genre set: Research article abstracts and introductions in two disciplines. English for Specific Purposes, 24(2), 141-156. http://dx.doi.org/10.1016/j.esp.2002.10.001

Santos, M. B. (1996). The textual organization of research paper abstracts in applied linguistics. Text, 16(4), 481-499.

Swales, J. M. (1990). Genre Analysis: English in academic and research settings. Cambridge: Cambridge University Press.

Vázquez, I., \& Giner, D. (2008). Beyond mood and modality: Epistemic modality markers as hedges in research articles. A cross-disciplinary study. RevistaAlicantina de EstudiosIngleses, 21, 171-190.

\section{Copyrights}

Copyright for this article is retained by the author(s), with first publication rights granted to the journal.

This is an open-access article distributed under the terms and conditions of the Creative Commons Attribution license (http://creativecommons.org/licenses/by/3.0/). 